\title{
Expression of undifferentiated embryonic cell transcription factor-1 (UTF1) in breast cancers and their matched normal tissues
}

\author{
Chaoyang $\mathrm{Xu}^{1,2}$, Ying Zhou ${ }^{1 *}$ and Wei Chen ${ }^{1 *}$
}

\begin{abstract}
Objectives: Undifferentiated embryonic cell transcription factor-1 (UTF1) plays a critical role in the developmental timing during embryonic development. However, there is little paper dealing with UTF1 expressed in adult tissues. In the present study, we evaluate the expression of UTF1 in breast cancer and its correlation with clinicopathological parameters.
\end{abstract}

Methods: Real-time polymerase chain reaction (real-time PCR) was applied to detect the expression of UTF1 mRNA in the 55 pairs of samples of breast cancer tissues and match normal tissues. $\Delta \Delta C T$ method was used to evaluate the relative quantity of target mRNA expression.

Results: Among the 55 pairs of samples of breast cancer tissues and match normal tissues adjacent to the tumor, the UTF1 mRNA levels in normal tissues were significantly higher than those observed in breast cancer tissues $(p<0.001)$. UTF1 mRNA levels expression correlated with lymph node metastasis $(p=0.002)$ and tumor size $(p<0.001)$.

Conclusions: Expression of UTF1 in breast cancer tissues were confirmed in this study. Decreased expression of UTF1 mRNA in breast cancer tissues was maybe one of the factors impact on tumorigenes in breast cancer patients.

Keywords: Breast cancer, UTF1, Polymerase chain reaction (PCR), Metastasis, Lymph node

\section{Introduction}

Currently breast cancer remains one of the most common cancers worldwide, and one of the leading causes of cancer related death in the word. Identification of biological markers ability to predict risk of prognosis in breast cancer is limited. To improve the clinical outcome of patients with advanced breast carcinoma, it is necessary to target novel biomarker genes, which appear to be involved in carcinoma development, as we had described previously $[1,2]$.

Previous reports have indicated that there was a possible correlation of undifferentiated embryonic cell transcription factor-1 (UTF1) with the biological of cancer cell [3]. And the low expression of UTF1 may connect with poorer prognosis among patients with cervical cancer [4].

\footnotetext{
*Correspondence: mtybb2010@163.com; cwzjsx5018@163.com 'Department of Breast and Thyroid Surgery, Shaoxing People's Hospital, Shaoxing Hospital of Zhejiang University, Shaoxing, Zhejiang 312000, China Full list of author information is available at the end of the article
}

Undifferentiated embryonic cell transcription factor-1 (UTF1), a transcriptional co-activator, was first isolated and identified from mouse F9 embryonic carcinoma cells [5]. The human UTF1 gene is located on chromosome 10q26 and consists of two exons and one short intron, which plays a critical role in the developmental timing during embryonic development [6,7]. UTF1 is readily expressed in embryos and embryonic stem cells, but it is either undetectable or its expression remains at low levels in normal adult tissues, suggesting that UTF1 may play a critical role in cell proliferation and/or differentiation during embryonic development.

Recently, UTF1 confirmed the ability to facilitate the reprogramming of human somatic cells to induced pluripotent stem (iPS) cells [8]. Thus, UTF1 plays an important role in stem cells, and the expression of UTF1 cancer cells may have stem cell-like features. This prompted us to evaluate UTF1 status in human beast cancer. In addition, UTF1 has been reported to bind to a 
specific subset of mRNAs and modulate many gene translations, including those for $\mathrm{p} 27$ and Oct-3/4 [9].

The expression of UTF1 was subsequently detected in germ cell neoplasms [10], and cervical cancer [4]. Although UTF1 has been extensive studied in other cancers, no investigation has been conducted in breast cancer. We hypothesize that UTF1 may play a role in the oncogenesis of breast cancer. The present study was undertaken to examine the expression of UTF1 in breast cancer tissues by using a validated specific and sensitive real-time quantitative PCR assay. Here, we examined fifty-five cases of breast cancer tissues for the potential difference of UTF1 expression in breast cancer tissues and their matched normal tissues, and to assess the relationship between UTF1 expression and clinicopathological parameters in breast cancer patients.

\section{Materials and methods Case selection}

Specimens were obtained from 55 patients who underwent surgery of breast cancer at the Department of Breast and Thyroid Surgery of Shaoxing Hospital of Zhejiang University, between July 2012 and November 2013. Informed consent was obtained from all patients, and the study was conducted according to the guidelines of the Hospital Ethics Committee. The patients aged 35 to 73 years (mean 58.7 years). The correlation between the expression of UTF1 and clinicopathologic parameters including age, differentiation statue and pTNM pathological classification according to the International Union against Cancer (UICC) were evaluated. The clinicopathologic feature of the 55 cases were summarized in Table 1.

\section{RNA extraction and CDNA synthesis}

Total RNA was extracted from fleshly frozen gastric tissues using the Trizol reagent (Invitrogen life Technologies, USA). Total RNA was reverse reverse-transcribed into single-strand complementary DNA (cDNA) using moloneymurine leukemia (M-MLV) reverse transcriptase (Promega, Madison,WI, USA). Briefly, the RNAwas denatured by heating for $5 \mathrm{~min}$ at $70^{\circ} \mathrm{C}$, cooled on ice, and then used for reverse transcription $(2 \mu \mathrm{g}$ of total RNA, $25 \mathrm{U}$ of RNAse inhibitor, $0.5 \mathrm{mM}$ each of dNTPs, $1.5 \mu \mathrm{M}$ reverse primer and 200U of M-MLV reverse transcriptase in a total volume of $25 \mu \mathrm{l})$. For reverse transcription, tubes were incubated at $42^{\circ} \mathrm{C}$ for $60 \mathrm{~min}$, followed by rapid cooling.

\section{Real-time quantitative PCR}

Real-time RT-PCR analyses were performed with the ABI Prism 7500 sequence detection system (Applied Biosystems, Foster City, CA). $25 \mu \mathrm{l}$ reaction mixture containing $2 \mu \mathrm{l}$ of cDNA template, $1 \mu \mathrm{l}$ each of sense and anti-sense primers,
Table 1 Clinicopathologic characteristics of 55 cases of patients with breast cancer

\begin{tabular}{lll}
\hline Clinicopathologic parameter & Case (n) & $\%$ \\
\hline Age & & \\
$\leqq 35$ & 5 & $9.1 \%$ \\
$>35$ & 50 & $90.9 \%$ \\
Tumor size (cm) & & \\
$\quad \leq 2$ & 36 & $65.5 \%$ \\
$>2$ & 19 & $34.5 \%$ \\
Histological grading & & \\
I-II & 9 & $16.4 \%$ \\
III & 46 & $83.6 \%$ \\
Hormone-receptor & & \\
ER (+)/PR (+) & 23 & $41.8 \%$ \\
ER (+)/PR (-) & 7 & $12.7 \%$ \\
ER (-)/PR (+) & 4 & $7.3 \%$ \\
ER (-)/PR (-) & 21 & $31.2 \%$ \\
Lymph node metastasis & & \\
Yes & 24 & $56.4 \%$ \\
No & 31 & \\
\hline
\end{tabular}

$1 \times$ SYBR Green Universal PCR Mix was amplified as follow: denaturation at $95^{\circ} \mathrm{C}$ for $10 \mathrm{~min}$ and 40 cycles at $95^{\circ} \mathrm{C}$ for $30 \mathrm{~s}, 55^{\circ} \mathrm{C}$ for $30 \mathrm{~s}$ and $72^{\circ} \mathrm{C}$ for $40 \mathrm{~s}$. Real-time quantitative PCR reaction was performed in triplicate for each sample and a mean value of glyceraldehyde 3phosphate dehydrogenase (GAPDH) used to calculate mRNA levels. Quantitative analysis was performed using the comparative CT method [11,12]. The UTF-1 mRNA copy numbers in normal and tumor tissues were normalized to mRNA copy numbers of the house keeping gene, GAPDH to give a value $\triangle \mathrm{CT}$. This final value was to determine changes in expression of UTF-1 in each sample. The primer sequences for UTF-1 were as follows: forward primer 5'- ATGGGGCTGCTGGGCGACAAC G-3', reverse primer 5'- GGGGAGGCGTCCGCAGAC TTCG-3'. The primers for GAPDH were taken from a previously published assay [13]. Fluorescent data were converted into RQ measurements, which stand for relative expression automatically by the SDS system software and exported to Microsoft Excel. Thermal dissociation plots were examined for biphasic melting curves, indicative of whether primerdimers or other nonspecific products could be contributing to the amplification signal.

Table 2 Relative quantity of UTF-1 mRNA in breast cancer tissues and match normal tissues

\begin{tabular}{llll}
\hline & Tumor tissue & Normal tissues & $\mathbf{P}$ \\
\hline Relative UTF-1 expression & $1.97 \pm 0.161$ & $7.47 \pm 1.01$ & $<0.001$ \\
\hline
\end{tabular}


Table 3 Correlation between the expression of UTF-1 mRNA and number of metastasis lymph nodes, tumor size

\begin{tabular}{llll}
\hline & $\begin{array}{l}\text { UTF-1 expression } \\
\text { level } \leqq \mathbf{1 . 5 1 7}\end{array}$ & $\begin{array}{l}\text { UTF-1 expression } \\
\text { level }>\mathbf{1 . 5 1 7}\end{array}$ & $\mathbf{P}$ \\
\hline $\begin{array}{l}\text { Number of metastasis } \\
\text { lymph nodes }\end{array}$ & $0.33 \pm 0.56$ & $1.75 \pm 2.12$ & $\mathrm{p}=0.002$ \\
Tumor size & $1.34 \pm 0.60$ & $2.46 \pm 1.28$ & $(\mathrm{p}<0.001)$ \\
\hline
\end{tabular}

\section{Statistical analysis}

Statistical analysis was conducted using the statistical program SPSS 15.0 for Windows (SPSS, Chicago, IL, USA). Pre-treatment characteristics were analyzed using the 2-tailed $\mathrm{x}^{2}$ test. The 2-tailed $\mathrm{t}$-test was used to evaluate the correlation between UTF-1 expression and clinicopathologic parameters.

\section{Results}

Expressions of UTF-1 mRNA in breast cancer tissues by real-time $\mathrm{PCR}$

As shown in Table 2, of the 55 samples of breast cancer tissues and matched normal tissues adjacent to the tumor, expression of UTF-1 was detected in total samples. In normal tissues, the UTF-1 mRNA levels ranged from 0.039 to 41.96 with a median of 20.16 . In breast cancer tissues, the UTF-1 mRNA levels ranged from 0.008 to 6.263 with a median of 1.517. The UTF-1 mRNA levels in normal tissues were significantly higher than those observed in breast cancer tissues $(\mathrm{p}<0.001)$.

\section{Correlation between UTF-1 and clinicopathological parameter}

According to median expression level of UTF-1, 55 cases of breast cancer patients were divided into two groups, high UTF-1 expression group (UTF-1 expression level >1.517) and low UTF-1 expression group (UTF-1 expression level $\leqq 1.517$ ). The mean number of metastasis lymph nodes in high UTF-1 group is lower than low UTF-1 expression group ( 0.33 vs. 1.75$)$, the differences among them had statistically significant $(\mathrm{p}=0.002)$ (Table 3$)$. Moreover, tumor size was different between high expression UTF-1 versus low expression UTF-1 (1.34 vs. 2.46), the difference also have statistically significant $(\mathrm{p}<0.001)$ (Table 3).

\section{Discussion}

In the present study, we found the relative quantity of UTF-1 mRNA mRNA in 55 samples of breast cancer tissues as determined by real-time PCR. UTF- 1 mRNA was expressed more predominantly in normal tissues adjacent to the tumor than it was expressed in breast cancer tissues. We showed that UTF-1 was lower expressed in breast cancer tissues than corresponding normal tissues. Previous studies have reported that UTF-1 is expressed in various human epithelial-type neoplasias, such as cervical cancer [4]. At present, Mouallif et al. evaluated UTF1 expression levels immunohistochemically in eight normal epithelia including breast (prostate, endometrium, bladder, colon, oesophagous, lung and kidney) and their corresponding tumors in a recent paper [14].

In the current study, real-time quantitative PCR was used to compare the expressions of UTF- 1 mRNAs in 55 breast cancers and their matched normal tissues, which allows detecting UTF-1expression in breast tissues with very low level. Furthermore, we correlated these findings with the clinicopathological parameter of the breast cancers. The result showed that the low expression level of UTF-1 mRNAs in breast cancer patients was significantly associated with metastasis lymph nodes and tumor size. Our present study clarify that UTF-1 protein could act as a potential biomarker for prognosis assessment of breast cancer. Related mechanism is worthy of further investigation.

Previous studies have shown the expression of UTF-1 cells was identified in a subpopulation of stem cell-like cells [15] and the expression of UTF-1 may influence the susceptibility of cancer cells to chemotherapeutic agents and radiotherapy. These data suggested that positive expression of UTF-1 impact on cancer patients' survival not only influence the susceptibility of cancer cells to chemotherapeutic agents, but also other mechanism such as cell proliferation [16], stem cell-like features [17,18].

Recently, it was reported that the UTF1-overexpressing cells transactived p27Kip1 resulting in G1/S arrest, which may provide an explanation for UTF1 functions in cervical carcinogenesis. The similar results may present in breast cancer patients. In summary, our study demonstrated that the expression level of UTF1 may play a role in the oncogenesis and may serve as a biomarker for prognosis. Based on our findings, UTF1 gene could be a potential target for the treatment of breast cancer. The findings of this study present a novel knowledge of UTF1 and a potential future prospect for breast cancer treatment.

\section{Competing interests}

The authors declare that they have no competing interests.

\section{Authors' contributions}

CX conceived and designed the experiments. $C X$ and $Y Z$ performed the experiments. WC performed statistical analysis of all data. CX wrote the paper. All authors are in agreement with the content of the manuscript and this submission. All authors read and approved the final manuscript.

\section{Grant support}

Zhejiang Nature Science Foundation of China Q13H160045 (Chaoyang Xu), Science and Health Care Foundation grant Zhejiang, China 201345046, 201468770 (Chaoyang Xu), Shaoxing nonprofit technology applied research projects of China 2012B70055 (Chaoyang Xu), and Medical Association research Clinical funds of China 2012ZYC-A75 (Liming Huang).

\section{Author details}

'Department of Breast and Thyroid Surgery, Shaoxing People's Hospital, Shaoxing Hospital of Zhejiang University, Shaoxing, Zhejiang 312000, China. 2Department of Medical Research Center, Shaoxing People's Hospital, Shaoxing Hospital of Zhejiang University, Shaoxing, Zhejiang, China. 
Received: 12 July 2014 Accepted: 24 October 2014

Published online: 12 November 2014

\section{References}

1. Xie SD, Xu CY, Shen JG, Jiang ZN, Wang LB: HER 2/neu protein expression in gastric cancer is associated with poor survival. Mol Med Rep 2009, 2:943-946.

2. Xu CY, Guo JL, Jiang ZN, Xie SD, Shen JG, Shen JY, Wang LB: Prognostic role of estrogen receptor alpha and estrogen receptor beta in gastric cancer. Ann Surg Oncol 2010, 17:2503-2509.

3. Kristensen DM, Nielsen JE, Skakkebaek NE, Graem N, Jacobsen GK, Rajpert-De Meyts E, Leffers H: Presumed pluripotency markers UTF-1 and REX-1 are expressed in human adult testes and germ cell neoplasms. Hum Reprod 2008, 23:775-782.

4. $\mathrm{Wu} \mathrm{XL}$, Zheng PS: Undifferentiated embryonic cell transcription factor-1 (UTF1) inhibits the growth of cervical cancer cells by transactivating p27Kip1. Carcinogenesis 2013, 34:1660-1668.

5. Okuda A, Fukushima A, Nishimoto M, Orimo A, Yamagishi T, Nabeshima Y, Kuro-o M, Nabeshima Y, Boon K, Keaveney M, Stunnenberg HG, Muramatsu M: UTF1, a novel transcriptional coactivator expressed in pluripotent embryonic stem cells and extra-embryonic cells. EMBO J 1998, 17:2019-2032

6. Fukushima A, Okuda A, Nishimoto M, Seki N, Hori TA, Muramatsu M: Characterization of functional domains of an embryonic stem cell coactivator UTF1 which are conserved and essential for potentiation of ATF-2 activity. J Biol Chem 1998, 73:25840-25849.

7. Nishimoto M, Fukushima A, Okuda A, Muramatsu M: The gene for the embryonic stem cell coactivator UTF1 carries a regulatory element which selectively interacts with a complex composed of Oct-3/4 and Sox-2. Mol Cell Biol 1999, 19:5453-5465.

8. Pfannkuche K, Fatima A, Gupta MK, Dieterich R, Hescheler J: Initial colony morphology-based selection for iPS cells derived from adult fibroblasts is substantially improved by temporary UTF1-based selection. PLOS One 2010, 5:e9580.

9. Liu A, Cheng L, Du J, Peng Y, Allan RW, Wei L, Li J, Cao D: Diagnostic utility of novel stem cell markers SALL4, OCT4, NANOG, SOX2, UTF1, and TCL1 in primary mediastinal germ cell tumors. Am J Surg Pathol 2010, 34:697-706.

10. Wang P, Li J, Allan RW, Guo CC, Peng Y, Cao D: Expression of UTF1 in primary and metastatic testicular germ cell tumors. Am J Clin Pathol 2010, 134:604-612.

11. Schmittgen TD, Livak KJ: Analyzing real-time PCR data by the comparative C(T) method. Nat Protoc 2008, 3:1101-1108.

12. Livak KJ, Schmittgen TD: Analysis of relative gene expression data using real-time quantitative $P C R$ and the $2(-$ Delta Delta $C(T))$ Method. Methods 2001, 25:402-408.

13. Xu C, Shen J, Xie S, Jiang Z, Huang L, Wang L: Positive expression of Lin28 is correlated with poor survival in gastric carcinoma. Med Oncol 2013, 30:382.

14. Mouallif M, Albert A, Zeddou M, Ennaji MM, Delvenne P, Guenin S: Expression profile of undifferentiated cell transcription factor 1 in normal and cancerous human epithelia. Int J Exp Pathol 2014, 95:251-259.

15. Kues WA, Herrmann D, Barg-Kues B, Haridoss S, Nowak-Imialek M, Buchholz T, Streeck M, Grebe A, Grabundzija I, Merkert S, Martin U, Hall VJ, Rasmussen MA, Ivics Z, Hyttel P, Niemann H: Derivation and characterization of sleeping beauty transposon-mediated porcine induced pluripotent stem cells. Stem Cells Dev 2013, 22:124-135.

16. Lin $\mathrm{CH}$, Yang $\mathrm{CH}$, Chen YR: UTF1 deficiency promotes retinoic acid-induced neuronal differentiation in P19 embryonal carcinoma cells. Int J Biochem Cell Biol 2012, 44:350-357.

17. Brown S, Teo A, Pauklin S, Hannan N, Cho CH, Lim B, Vardy L, Dunn NR, Trotter M, Pedersen R, Vallier L: Activin/Nodal signaling controls divergent transcriptional networks in human embryonic stem cells and in endoderm progenitors. Stem Cells 2011, 29:1176-1185.

18. Kooistra SM, van den Boom V, Thummer RP, Johannes F, Wardenaar R, Tesson BM, Veenhoff LM, Fusetti F, O'Neill LP, Turner BM, De Haan G, Eggen BJ: Undifferentiated embryonic cell transcription factor 1 regulates ESC chromatin organization and gene expression. Stem Cells 2010, 28:1703-1714.

doi:10.1186/s12935-014-0116-6

Cite this article as: Xu et al.: Expression of undifferentiated embryonic cell transcription factor-1 (UTF1) in breast cancers and their matched normal tissues. Cancer Cell International 2014 14:116.

\section{Submit your next manuscript to BioMed Central and take full advantage of:}

- Convenient online submission

- Thorough peer review

- No space constraints or color figure charges

- Immediate publication on acceptance

- Inclusion in PubMed, CAS, Scopus and Google Scholar

- Research which is freely available for redistribution

Submit your manuscript at www.biomedcentral.com/submit
C Biomed Central 